\title{
Primary Care Physician Perspectives about Antipsychotics and Other Medications for Symptoms of Dementia
}

\author{
J. William Kerns, MD, Jonathan D. Winter, MD, Katherine M. Winter, CFNP, \\ Terry Boyd, PhD, and Rebecca S. Etz, PhD
}

Background: Guidelines, policies, and warnings have been applied to reduce the use of medications for behavioral and psychological symptoms of dementia (BPSD). Because of rare dangerous side effects, antipsychotics have been singled out in these efforts. However, antipsychotics are still prescribed "off label" to hundreds of thousands of seniors residing in nursing homes and communities. Our objective was to evaluate how and why primary-care physicians (PCPs) employ nonpharmacologic strategies and drugs for BPSD.

Methods: Semi-structured interviews analyzed via template, immersion and crystallization, and thematic development of 26 PCPs (16 family practice, 10 general internal medicine) in full time primarycare practice for at least 3 years in Northwestern Virginia.

Results: PCPs described 4 major themes regarding BPSD management: (1) nonpharmacologic methods have substantial barriers; (2) medication use is not constrained by those barriers and is perceived as easy, efficacious, reasonably safe, and appropriate; (3) pharmacologic policies decrease the use of targeted medications, including antipsychotics, but also have unintended consequences such as increased use of alternative risky medications; and (4) PCPs need practical evidence-based guidelines for all aspects of BPSD management.

Conclusions: PCPs continue to prescribe medications because they meet patient-oriented goals and because PCPs perceive drugs, including antipsychotics and their alternatives, to be more effective and less dangerous than evidence suggests. To optimally treat BPSD, PCPs need supportive verified prescribing guidelines and access to nonpharmacologic modalities that are as affordable, available, and efficacious as drugs; these require and deserve significant additional research and payer support. Community PCPs should be included in BPSD policy and guideline development. ( $\mathrm{J}$ Am Board Fam Med 2018;31: 9-21.)

Keywords: Antipsychotic Agents, Dangerous Behavior, Dementia, Policy, Primary Care Physicians, Virginia

Dementia is diagnosed based on cognitive decline with evidence of memory loss, but noncognitive psychiatric symptoms are seen in dementia of all etiologies and stages. ${ }^{1,2}$ Referred to as behavioral

This article was externally peer reviewed.

Submitted 14 June 2017; revised 18 August 2017; accepted 23 August 2017.

From the Shenandoah Family Practice Residency, Virginia Commonwealth University, Front Royal (JWK, JDW, KMW, TB); and the Department of Family Medicine and Population Health, Virginia Commonwealth University, Richmond (JWK, JDW, RSE).

Funding: This study was funded in part by Virginia Commonwealth University's Clinical and Translational Science Award (UL1TR000058) from the National Center for Advancing Translational Sciences and the Center for Clinical and psychological symptoms of dementia (BPSD), these include disordered mood, psychosis, inappropriate behaviors, and motor symptoms. ${ }^{1,3}$ These noncognitive neuropsychiatric symptoms are often the most intrusive, debilitating, and detrimental for patients and caregivers in terms of quality of life and health outcomes. Furthermore, BPSD symptoms are frequently critical and direct drivers of

and Translational Research's Endowment Fund of Virginia Commonwealth University.

Conflict of interest: none declared.

Corresponding author: J. William Kerns MD, VCU-Shenandoah Family Practice Residency, 140 West 11 St, Front Royal, VA 22630 (E-mail: bkerns@valleyhealthlink.com). 
institutionalization and the economic cost of dementia. $^{4,5}$

Although evidence proving the effectiveness of nonpharmacologic approaches for BPSD across domains of care is lacking, a growing body of literature demonstrates that these skills, techniques, activities, therapies, and personalized interventions can improve quality of life and help to manage certain symptoms and behaviors. ${ }^{6-8}$ While these methods are safer for patients than medications, their individualized nature requires greater investments of time, effort, expertise, and financial resources. ${ }^{10}$ Also, reimbursement for these services is often poor. For all these reasons, they are likely underused in all settings including long-stay facilities. ${ }^{6,7,10-12}$ These techniques are also more effective for some BPSD than for others. ${ }^{7}$ For example, an agitated patient can often be calmed by music, touch, and aromatherapy, especially in combination with other personalized approaches, whereas those who are hallucinating are more likely to need medication as part of the treatment plan. ${ }^{7,9,13-15}$ At times even optimally applied nonpharmacologic therapies simply do not work because of numerous factors, including disease variation and progression. ${ }^{8,16}$

Medications used "off label" for BPSD include anxiolytics, antidepressants, cognitive enhancers, antipsychotics, and anticonvulsant mood stabilizers. Benzodiazepines, prescribed for anxiety and agitation, increase risks of sedation, confusion, falls, and fractures. ${ }^{17,18}$ Cognitive enhancers (N-methyl$\mathrm{D}$-aspartate antagonists and cholinesterase inhibitors) have been shown to have small statistically significant effects in ameliorating BPSD, but many patients already take these drugs. ${ }^{19,20}$ Serotonergic drugs can improve depression and anxiety but have limited efficacy for BPSD. ${ }^{21}$ Although they are generally well tolerated, even these medications convey potential risks; citalopram has been shown to be helpful for certain BPSD, but it blunts cognition and results in worrisome electrocardiographic changes. ${ }^{22}$ Anticonvulsant mood stabilizers are used for agitation and aggression in particular, although trials evaluating their efficacy and safety for frail elderly are scant, and results are mixed. ${ }^{23-37}$ Some anticonvulsants, such as valproate and carbamazepine, carry US Food and Drug Administration (FDA) boxed warnings because of hepatic and bone marrow toxicities. ${ }^{38,39}$

Antipsychotic medications have the best evidence for improving BPSD, although they work only $25 \%$ to $30 \%$ of the time. ${ }^{40,41}$ While their benefit in BPSD is modest, their risk profile is extensive. In addition to extrapyramidal symptoms and sedation, antipsychotics are associated with confusion, falls, and aspiration events. ${ }^{42}$ However, increases in strokes, heart attacks, and mortality associated with the use of typical and atypical antipsychotics earned both FDA boxed warnings. ${ }^{42-44}$

In addition to the FDA warnings, political and regulatory spotlights have focused on medication use for BPSD. Inappropriate antipsychotic prescribing for BPSD has been labeled "chemical restraint" and "elder abuse." 45 Some states have proposed legislation to require written informed consent for their use. ${ }^{46}$

The long-standing agenda of the Centers for Medicare \& Medicaid Services (CMS) to curb drugs for BPSD was codified in the 1987 Nursing Home Reform Act, which prohibited the chemical restraint of patients in nursing homes. ${ }^{47}$ In March 2012, as part of a concerted effort to check off-label prescribing of antipsychotics for BPSD, CMS launched the National Initiative to Improve Behavioral Health \& Reduce the Use of Antipsychotic Medications in Nursing Home Residents ${ }^{48}$, subsequently renamed the National Partnership to Improve Dementia Care in Nursing Homes. The rate of antipsychotic use in long-stay facilities was made a quality measure, published through the Medicare Nursing Home Compare website (https://www. medicare.gov/nursinghomecompare/search. html?), and factored into Medicare's 5-star facility rating. In nursing homes, pharmacists also supervise mandatory periodic reviews of all psychoactive medications to encourage consideration for weaning or reducing doses. ${ }^{48}$ Since the initiative's debut, antipsychotic use in nursing homes has decreased steadily. CMS's initial goal of a $15 \%$ nationwide reduction was achieved in the final quarter of 2013, and by the fourth quarter of 2016 the national rate was down $33 \%$, from $23.8 \%$ to $16 \% .{ }^{49,50}$

National and international guidelines for medical management of BPSD all state that antipsychotics should be used only when other measures fail and with appropriate discussion of the risks and benefits. According to the American Geriatric Society and respective national and provincial Canadian groups, only potential harm to self or others justifies their use. ${ }^{51,52}$ However, the American Psychiatric Association, the American Alzheimer's Association, and the British National Institute for 
Health Care and Excellence guidelines liberalize indications to include refractive patient distress. $^{53-56}$

Despite evidence of only modest benefit and proven severe risk, the context of purposeful efforts from the FDA, CMS, and state legislation, and the censure of geriatric societies and patient advocacy groups, physicians continue to prescribe antipsychotics and other medications for BPSD to hundreds of thousands of patients in US nursing homes and communities. ${ }^{50}$ The reasons for this apparent conundrum are not well understood, and investigation in this area has been scant. This study sought to explore American primary care physicians' use of nonpharmacologic modalities and drugs to treat these challenging symptoms.

\section{Methods}

We adapted the qualitative research framework posited by Leeman and Sandelowski ${ }^{57}$ for "Designing Qualitative Studies to Elicit Practice-Based Evidence," in this study examining "What aspects of the practice context may interact with interventions or strategies to moderate patient or system outcomes?"

We administered semistructured interviews of 26 participants (primary care physicians [PCPs]) to determine their experiences with and perceptions of medication and nonpharmacologic management of BPSD. (See the Appendix for an abbreviated interview guide.) Telephone interviews (1-on-1) averaged 45 minutes (range, 20-65 minutes). Participants were interviewed by family physicians (JWK, JDW) from their district (see 'Setting' below).

\section{Participants and Setting}

Our participants were 26 PCPs from the 5 counties of the Lord Fairfax Health District of northwestern Virginia who were involved in direct patient care $>20$ hours/week and had been in primary care practice within the district $>3$ years. We did not stipulate the percentage of patients with dementia included in the PCPs' patient panels. Participants were recruited in person, over the telephone, and through E-mail. An honorarium of $\$ 50$ was offered. Our initial goal was to have 8 PCPs who cared for patients in nursing homes and 16 who did not, in order to reach data saturation within each group, and to have a diverse group of physicians with overall project saturation of around 24 participants. ${ }^{58,59}$ However, half our participants (13) had at least 1 patient in a nursing home facility. Of those 13,10 had $>5$ patients in nursing homes, and these 10 were used for comparative analysis with the remaining 16 . We did achieve data saturation within those groups and for the overall group in our final analysis. ${ }^{58}$ We further discovered that views of all PCPs were largely congruent, despite training in family or internal medicine, despite caring for patients in nursing homes (or not), and despite duration of practice. Results presented here (except where noted) reflect the entire PCP group.

\section{Data Analysis}

Transcriptions of audio-recorded interviews were organized and coded using Atlas.ti. Codes for use in template analysis were developed both inductively and deductively, yielding a priori codes that were honed and augmented by emergent findings. ${ }^{60}$ The coding team (JWK, KMW, TB) developed a preliminary code book based on the research questions and relevant literature. After 6 to 8 interviews, the team applied an immersion and crystallization process of reading and rereading transcripts to refine codes while also allowing previously unpredicted findings to be added to the code book. ${ }^{58}$ This process occurred iteratively until the code book was well defined and coding saturation was reached, in this case 3 cycles. Coding then proceeded independently for all transcripts, after which the team came together to resolve coding differences via negotiated consensus to ensure strong intercoder agreement. ${ }^{61}$

Preliminary themes were identified through the analysis of coding elements. Two authors (JWK, JDW) used a method of metaphor and allegory described by Ryan and Bernard ${ }^{62}$ to further delineate and appraise code patterns and prospective significant "themes and subthemes": "Analysis ... becomes the search for metaphors in rhetoric and deducing the schemas or underlying themes that might produce those metaphors." These were inspected iteratively over 3 cycles of meetings, during which disconfirming evidence was sought for those themes and differences were resolved through negotiated consensus. From these metaphors 4 major themes emerged and were organized into the findings presented in the Results. All authors vouch for the validity of these findings. 
Dr. Etz audited the ongoing analytic process and guided the team's efforts. This study was approved by the Institutional Review Board of Virginia Commonwealth University, Richmond.

\section{Results \\ Participants}

We interviewed 26 PCPs, 16 trained in family medicine and 10 in internal medicine. Among the internists, 2 had additional qualifications in geriatrics. Our participants included 19 men and 7 women, with an mean age of 50 years (range, 35-69 years) and an average practice duration of 19 years (range, 4-38 years). They self-identified as white $(\mathrm{n}=21)$, Asian $(\mathrm{n}=3)$, and African American $(\mathrm{n}=$ 1); 1 participant declined to comment. Three had 1 patient in a nursing home and 10 had $>5$ patients in a nursing home (mean, 18 patients; range, 6-30 patients). Of the 10 PCPs with $>5$ patients in a nursing home, 6 were family physicians.

\section{Themes}

Four major themes were identified. Exemplar quotes are presented in Table 1.

\section{Theme 1: Nonpharmacologic BPSD Therapies Have Substantial Barriers}

All PCPs described services supporting dementia care as inadequate. That said, PCPs reported that few patients fully capitalized on all available resources. Family capabilities and involvement were noted as significant factors affecting optimal utilization. While all families were characterized as increasingly overwhelmed as the disease progressed, some families were depicted as extremely proactive and much more successful in identifying and using national and local resources. However, a majority of families were reported to struggle to identify and use these existing supports.

Most PCPs acknowledged they had little formal training in nonmedication therapies for dementia symptoms and that time constraints made any personalized instruction by them untenable. In addition, the changing landscape of community assistance and resources was described as so variable that maintaining awareness of current availability was nearly impossible. The few services that PCPs could describe as consistent, available, and helpful (for example, "in-home services" from a geriatric organization) were characterized as overwhelmed by demand.

Similar to the services currently available to patients with diabetes via trained diabetes educators, some PCPs imagined a "navigator" or counselor who could serve as a guide to shepherd families through BPSD or for all aspects of dealing with the disease process. All nonpharmacologic measures (eg, hired caregivers, assisted living) were acknowledged to involve significant, often prohibitive, costs.

PCPs stated that nonpharmacologic therapies are essential first-line measures that are helpful for BPSD to some extent all the time. However, PCPs viewed these modalities as having only about a $50 \%$ efficacy to relieve bothersome symptoms and as eventually losing effectiveness as dementia and BPSD worsened. The PCPs also lamented that the evidence for the efficacy of nonpharmacologic BPSD therapies lacked the robustness and generalizability they desired.

\section{Theme 2: Medications Are "Easy," Effective, Safe, and Address Patients' Needs}

In stark contrast to nonpharmacologic modalities, no PCP reported cost as a barrier to medication use. Medications were said to be the easiest BPSD solution for patients, caretakers, and doctors: they are affordable, easily available, require minimal training, and quick to take effect.

In addition to being "easy," almost all PCPs indicated that medications worked at least half of the time, even for recalcitrant symptoms. Severe side effects were almost never knowingly discerned, and all classes of medications seemed to convey roughly the same collection of adverse effects, of which the most concerning and common were sedation and falls. Specifically, of the 26 PCPs interviewed, only 2 described direct experience with possible severe side effects from a medication. One PCP from the nursing home group described a colleague's patient who experienced a stroke soon after initiating antipsychotic therapy. Because stroke is not rare among patients in nursing homes, he wondered, but was uncertain, whether the medication was the cause. Another nursing home physician described a patient receiving a large dose of quetiapine and who had a seizure soon after arriving to his dementia unit. Because seizures occur with some regularity in this population, he suspected, but again was unsure, that the medication 
Table 1. Primary Care Physician Exemplar Quotations, by Theme

\begin{tabular}{|c|c|}
\hline Theme* & Quotations \\
\hline 1 & $\begin{array}{l}\text { "There's unfortunately not a lot of resources where we are for helping folks, or maybe I'm just not aware that they } \\
\text { exist." }\end{array}$ \\
\hline 1 & $\begin{array}{l}\text { "Well, it's mostly availability ... and that these types of services aren't readily known, and those that are, are } \\
\text { overwhelmed with requests. So, the access is more of an availability issue." }\end{array}$ \\
\hline 1 & "Neither the doctor nor the family has been trained to do [non-drug approaches] right." \\
\hline 1 & $\begin{array}{l}\text { "If I could sign up every family that I diagnose as a patient or every spouse or daughter, or caregiver to a dementia } \\
\text { navigation for the caregiver like a course, I think that would be so helpful because half of what we take care of is } \\
\text { caregiver support issues. They either don't know what to expect or they don't know if this is a normal part of } \\
\text { the process. Sometimes just assisting them in navigation of how to cope and handle situations that come up but } \\
\text { also what's going to be problems in the future, I think that would-that's a resource that I wish I had-a } \\
\text { caregiver navigation course. We have a diabetes education course, something like that I think that would be } \\
\text { really helpful." }\end{array}$ \\
\hline 1 & $\begin{array}{l}\text { "Counseling for caregivers, yes. And then, of course, helping the caregivers navigate situations in which their } \\
\text { behavior problems might escalate-try to defuse those." }\end{array}$ \\
\hline 1,2 & $\begin{array}{l}\text { "Early on, and if they've got other family members at home, it works out OK-like, reassurance, but if they're } \\
\text { alone or if there's another elderly spouse in the house, or if they start wandering, or if they see things that really } \\
\text { scare them, then the nonpharmacologic doesn't work very well." }\end{array}$ \\
\hline 1,2 & $\begin{array}{l}\text { "To be honest, I think by the time they come to us and are complaining, the advocate is complaining for the } \\
\text { patient, I think they've tried the reassurance and the nonpharmacologic things, and it's up to us to kind of step } \\
\text { in pharmacologically and help." }\end{array}$ \\
\hline 1,2 & $\begin{array}{l}\text { "Writing a prescription and accepting a prescription is often the easiest intervention for both the doctor and the } \\
\text { patient or family. The other interventions require effort on both ends and oftentimes expense and } \\
\text { inconvenience." }\end{array}$ \\
\hline 1,2 & $\begin{array}{l}\text { "There are short-term cheap ways to address these situations pharmacologically. The long-term, more definitive } \\
\text { approach is often more costly, and you run into barriers, too, with family members having to work outside the } \\
\text { home or having difficulty taking time off to manage that, as well." }\end{array}$ \\
\hline 2 & $\begin{array}{l}\text { "Well, that's almost like saying, 'Am I relying on somebody's insulin to treat their diabetes?' Well, of course I am, } \\
\text { 'cause it works. . . We're getting a phone call that they're screaming or they're complaining the police are out } \\
\text { to get them, and they're showing more of the psychotic-type behavior changes, it's nice to have medicines that } \\
\text { control that, because I feel that I'm actually doing the patient a service. And it's not just that I'm treating that } \\
\text { because they bother the staff, but rather that it's bothersome to the patient. . . I feel like I'm doing a good job } \\
\text { of addressing the patients." }\end{array}$ \\
\hline 2 & $\begin{array}{l}\text { "Is it better to medicate somebody or is it better to have their caregiver give up, where they have to be moved to } \\
\text { an institutionalized setting? . . For the majority of patients that's our goal." }\end{array}$ \\
\hline 2 & $\begin{array}{l}\text { Interviewer: Do you see the severe side effects that are described in the black box warnings in your patients? "No. } \\
\text { Have you? [laughs]" }\end{array}$ \\
\hline 2 & $\begin{array}{l}\text { Interviewer: OK. What kind of significant side effects do you look for in meds in general? "Well, obviously with } \\
\text { the SSRIs, it's serotonin syndrome. And I've unfortunately had that a couple of times. The benzos, obviously } \\
\text { you worry about oversedation, falls, things of that nature. The atypicals-you know, there's some issue of } \\
\text { increased mortality. Cardiovascular, which I have not seen. I haven't seen any of the worsening of depression, } \\
\text { suicidal-type behavior associated with any of those so far. But I have a fairly healthy fear of them." }\end{array}$ \\
\hline 3 & $\begin{array}{l}\text { "I see myself using less antipsychotics in this population now than I did } 10 \text { years ago." Interviewer: What diagnosis do } \\
\text { you use for prescribing the meds for behavioral issues? "Well, you know, there's only three diagnoses that will cover } \\
\text { those things [chuckles], so there has to be some element of psychosis if you're getting Seroquel. Now, if it's Remeron } \\
\text { it's gonna be probably major depression. If it's Depakote, it may be maybe some agitated features with some } \\
\text { depression . . . you can't use Alzheimer's dementia to get Seroquel covered in the nursing home." }\end{array}$ \\
\hline 3 & $\begin{array}{l}\text { "[In nursing homes] we can use benzos, but we stay away-there's virtually nobody on Seroquel or Risperidone or } \\
\text { any of that stuff. . . There's more trazodone use, and occasionally the morphine." }\end{array}$ \\
\hline 3 & $\begin{array}{l}\text { "The state regulators, they're not gonna mess with a psychiatrist like they would a generalist . . . and obviously the } \\
\text { patient's doing better and that's documented, and they're being looked at by psychiatry and looked at by me, so } \\
\text { a regulator in their right mind is not going to want to change that." }\end{array}$ \\
\hline 3 & $\begin{array}{l}\text { "[Regarding antipsychotics] I have not seen anything that has been truly alarming. I have seen side effects that } \\
\text { have resulted in discontinuation, but nothing that-nothing is coming to mind as far as significant morbidity." }\end{array}$ \\
\hline 3 & "[Benzodiazepines] definitely share the same types of safety concerns that I have with the antipsychotics." \\
\hline 3 & $\begin{array}{l}\text { "The cautions have become stronger over the years-the conversations that I have when a family member } \\
\text { approaches me with the typical exasperated, 'You gotta do something-you have to give my parent something to } \\
\text { calm them down,' I do have, hopefully at a level that they can understand, a discussion with them regarding the } \\
\text { fact that they may see that in the short term, their parent is more manageable with medication onboard, but } \\
\text { these medications have the risk of serious side effects, and assuming that I'm speaking to them as a power of } \\
\text { attorney, they need to make a risk/benefit decision as far as whether this is an intervention they want to try. } \\
\text { That's a conversation I probably was not having } 10 \text { years ago." }\end{array}$ \\
\hline
\end{tabular}




\begin{tabular}{l}
\hline Theme* Quotations \\
\hline 4 \\
"If you go back and you go through the American Academy of Family Practice and look at dementia . . they're \\
basically telling you to stay away from the medicines that almost every person ends up on anyway . . because \\
they never say what to do when [a non-drug approach] doesn't work . . try harder or something, and they just \\
need to say, 'This is the fallback if this doesn't work.' They have an algorithm for everything else; it has little \\
arrows going down saying what to do. For this one, they don't." \\
"It would be nice instead of having all of our guidelines say 'don't do, don't do, don't do, it'd be nice to find out \\
what we can do." \\
"I would love to not give these people these medications if somebody would give me a reasonable alternative, but I \\
have yet to see anything come out in the literature that will provide the sort of symptom relief that you're \\
looking for, that will allow these people some sort of functional ability . . because if I don't give it to them, \\
they have no quality of life and they are basically tormented by their illness . . . " \\
"I'm told that, at least in journal articles that I read, that I'm a bad doctor because we should be using all these \\
behavioral methods and so forth, but the bottom line is those other things don't work. I've talked to doctors \\
who've gotten special training in geriatric medicine and they will say the same thing, but ultimately all their \\
patients end up on the same things."
\end{tabular}

*Theme 1: nonpharmacologic behavioral and psychological symptoms of dementia (BPSD) therapies have substantial barriers; theme 2: medications for BPSD are "easy," efficacious, usually safe, and address patient needs; theme 3: consequences of current policies; theme 4: primary care physicians need supportive and evidenced guidelines.

played a role. Despite these experiences, both physicians continued to prescribe antipsychotic medications for BPSD. Otherwise, PCPs reported not seeing the dire effects of antipsychotics and other medications prescribed for BPSD described in FDA black box warnings. Except for occasional episodes of extrapyramidal symptoms, antipsychotics were said to have the same side effect and safety profiles as other medications used for BPSD.

PCPs stated that medication use was both crucial and appropriate to address 4 areas of patient needs: distress, safety, functionality, and care maintenance. Symptoms of distress often overlapped with safety, including agitation, paranoia, belligerence, hostility, aggressiveness, and wandering. Functionality was another important goal that PCPs viewed as justifying pharmacologic therapies. This included assisting sleep and allowing for interactions with others. Most PCPs asserted that using medications for BPSD allowed patients to remain at home or in assisted living, delaying unwanted transitions to higher levels of care.

\section{Theme 3: Consequences of Current Policies}

Physicians in practice $>10$ years acknowledged that they used medications for BPSD, including antipsychotics and benzodiazepines, less often and in lower doses than they previously had. Physicians with less experience did not note such changes. Most PCPs working in nursing homes stated that they are regularly challenged by required pharmacy queries about the use of all "psychiatric" or "behav- ioral" medications. These reviews, along with an increased awareness of risk from information published in journal articles and continuing medical education courses, were said to be among the reasons that they changed both their documentation and their prescribing. When using drugs for BPSD, almost all PCPs reported currently using more scrupulous documentation that details any discussion with families as well as why the medication was required. Most nursing home PCPs even adjusted their diagnoses to better support medication use, for example, "dementia with psychosis" when prescribing an antipsychotic. PCPs reported trying to minimize antipsychotic use for BPSD. However, they also reported increasing their use of other medications that had rarely been used for dementia symptoms, particularly singling out sedating antidepressants such as trazadone and anticonvulsant mood stabilizers such as valproate as examples of such changes. PCPs noted that psychiatric and neurologic consultations both in the outpatient setting and in nursing homes helped relieve diagnostic and administrative time burdens while shifting the risk of off-label prescribing to specialists. However, PCPs agreed that consultants used medications for BPSD as much or more than they would have.

PCPs described discussions with families about treating BPSD with medications as nuanced and challenging. Most PCPs acknowledged that this conversation was often longer and more detailed than in the past, often including an analysis of risks and benefits. However, PCPs found that such dis- 
cussions rarely resulted in medications not being used. PCPs stated that most community caregivers came to them with an urgent request for help only when they had exhausted known services and nonpharmacologic options. For long-stay patients, PCPs described significant variation between requests for medications from different facilities, and they were, in general, were more likely to expedite medication requests from trusted personnel whom they knew had already checked for other potential causes of BPSD and had applied maximal nondrug efforts.

\section{Theme 4: PCPs Need Supportive Evidence-Based Guidelines}

Many PCPs commented on the lack of proven guidelines for nonpharmacologic interventions for BPSD. Furthermore, almost all PCPs expressed frustration about not being adequately supported by evidence or assisted by guidelines and policies with regard to how to approach severely intrusive but not life-threatening BPSD when nonpharmacologic measures fail. All PCPs believed that medications are sometimes appropriate to treat patientoriented palliative goals, to relieve distress, or to improve quality of life, even in the absence of a direct threat of harm. All voiced dissatisfaction with guidelines or policies that, rather than assisting them in meeting such patient needs, characterized them as "bad doctors."

\section{Discussion}

PCPs identified many practical and logistic barriers to accessing nonpharmacologic therapies for their patients, of which money, time, and convenience were most significant. In direct contrast, no significant barriers were described to prescribing drugs for BPSD. Clearly, medication use is not likely to decline until alternative therapies receive better support.

Inherent in the PCP description of barriers to nondrug therapies is the conviction that medication use for BPSD can be reduced in all care settings through optimal use of these alternative modalities. Although this would necessitate overcoming the obstacles enumerated above, PCPs identified an opportunity to enhance such care simply by improving the use of services that are already available. That few families take full advantage of fragmented existing resources is consistent with what community caretakers have previously described. ${ }^{16}$ In addition, congruent with this suggestion, dementia "navigators" in Minnesota and "counselors" elsewhere have been shown to be of great benefit to families, optimizing support, personalizing therapies, and improving both patient and caregiver outcomes. $^{63}$

When alternative approaches failed or were unavailable, almost all PCPs readily used drugs, including antipsychotics, to address BPSD. Similar to other physician studies, but contrary to the pharmacologic literature, PCPs felt that medications worked the majority of the time. ${ }^{37,64}$ Contrary to data regarding harms, PCPs viewed medications as generally safe. No particular medication class was observed to have a singular risk profile, and no PCP was certain they had witnessed a "black box warning" event. As previously proposed, it may be that it is difficult to perceive rare medication-related effects against the backdrop of severe chronic morbidity. ${ }^{16}$ For example, distinguishing a 12-week survivorship rate of $97.7 \%$ from $96.5 \%$ for patients taking antipsychotics may not be clinically appreciable. $^{65}$

The discrepancy between PCPs' perceptions about medication efficacy and safety compared with what is proven may contribute to persistent medication use. How much increasing education about medication efficacy and side effects will change prescribing is unclear, because most PCPs showed reasonably detailed awareness of risks and warnings. This phenomenon is not unique to American PCPs; Dutch geriatricians, who clearly acknowledged expected increased morbidity and mortality from antipsychotic use, continued to prescribe them for "agitation" and "aggression." ${ }^{64}$ Similarly, increasing availability of specialty consultants for BPSD management may not reduce prescribing, because although PCPs viewed specialists as helpful, they described them as using antipsychotics and other medications at least as often as the referring PCPs.

In order to prescribe antipsychotics for someone with dementia, informed decisions are touted and legislation requiring informed consent has been proposed. ${ }^{46}$ However, the impact this would have on management approaches is unknown. Many PCPs in this study acknowledged having a different conversation now than a decade ago with families about treatment options for BPSD, often including more detailed discussion of benefits and risks. It is 
interesting, though, that PCPs reported that even detailed discussion of risks and adverse effects rarely resulted in a decision not to use medication. In addition, the amount of autonomy caregivers want in medication decisions varies from actively evaluating pros and cons and being the primary decision maker to deferring all medication decisions to the physician. ${ }^{16,65}$

FDA warnings, CMS efforts, and guidelines about antipsychotic use in patients with dementia have had multifaceted consequences for almost all the PCPs we interviewed. In nursing homes, periodic medication reviews overseen by pharmacists seemed to be effective in encouraging dose reductions and weaning. One resultant change was a decrease in antipsychotic use. Other consequences included changes in charting, changes in how neuropsychiatric diagnoses are reported, and an increase in the use of alternative drugs for BPSD which have real but not fully evaluated dangers. These unintended consequences merit more detailed evaluation and should be considered for future research.

PCPs all expressed frustration with policies and guidelines that did not support them in the management of intrusive symptoms when nonpharmacologic therapies fail. All PCPs felt that circumstances exist where medications are appropriate even in the absence of threat of harm. Beyond symptoms, PCPs felt that quality of life and other patient-oriented goals have to be considered when prescribing. A previously underappreciated patientoriented goal was the desire for the patient to stay in their own home. This is congruent with caregiver stakeholders who also had a palliative perspective for dementia care. ${ }^{16}$ While some policies and guidelines would endorse all such prescribing, it is contrary to others, and PCPs resent being characterized as "bad doctors." 45 Ongoing and appropriate medication reduction efforts may need to take these findings into consideration.

All PCPs expressed a need and desire for practical and evidence-based guidelines for how to effectively help patients with BPSD, both in their homes and in facilities, and including both medications and nonpharmacologic approaches.

\section{Strengths and Limitations}

Our study's strengths include a diverse sampling of experienced PCPs in the Lord Fairfax Health District of Virginia, who represent family and general internal medicine and who do and do not work with a significant number of patients in nursing homes.

Weaknesses include that the district is rural and our physicians were older, and mostly white men. Lacking are the perspectives of more ethnically diverse urban and suburban PCPs as well as other providers who actively care for patients with dementia. Teasing out differences between physicians in family medicine, physicians in internal medicine, and other practitioners, as well as variations in approaches used in different settings, may be feasible with larger investigations in other locales.

\section{Conclusions}

PCPs continue to prescribe medications for symptoms of dementia because they view them as safer and more effective than controlled studies report. They use drugs for symptoms with a direct threat of harm but also to meet patient-oriented goals, including easing patient suffering. PCPs endorse that increasing nonmedication methods for treating BPSD would decrease the need for drugs, but they also describe many barriers to the use of these methods. To decrease medication use, nonpharmacologic therapies will need to be as easy, available, and affordable as drugs - but this requires research and funding. Opportunities may exist to optimize the use of resources already present in communities. Increasing education about medication risks and increasing specialty support were not identified as factors likely to reduce medication use. Those who design guidelines and policies should consider recruiting community PCPs to participate in the development of clinically meaningful recommendations.

The authors thank the Shenandoah Valley Family Practice Residency for additional support. The authors are grateful to the family and internal medicine physicians of northwestern Virginia for their participation in this project, and to Christine Carlson Kerns for her assistance with early analysis. We are also grateful to the VCU Department of Family Medicine and Population Health, and to Dr. Anton Kuzel and Dr. Rebecca Aycock for their assistance.

To see this article online, please go to: http://jabfm.org/content/ 31/1/9.full.

\section{References}

1. Lyketsos CG, Lopez O, Jones B, Fitzpatrick AL, Breitner J, DeKosky S. Prevalence of neuropsychiatric symptoms in dementia and mild cognitive im- 
pairment: results from the cardiovascular health study. JAMA 2002;288:1475-83.

2. Galvin JE, Sadowsky CH, Nincds A. Practical guidelines for the recognition and diagnosis of dementia. J Am Board Fam Med 2012;25:367-82.

3. Tampi RR, Williamson D, Muralee S, et al. Behavioral and psychological symptoms of dementia: part I - epidemiology, neurobiology, heritability, and evaluation. Clin Geriatr 2011;19:41-6.

4. Buckley T, Fauth EB, Morrison A, et al. Predictors of quality of life ratings for persons with dementia simultaneously reported by patients and their caregivers: the Cache County (Utah) Study. Int Psychogeriatr 2012;24:1094-102.

5. Afram B, Stephan A, Verbeek H, et al; RightTimePlaceCare Consortium. Reasons for institutionalization of people with dementia: informal caregiver reports from 8 European countries. J Am Med Dir Assoc 2014;15:108-16.

6. Gitlin LN, Kales HC, Lyketsos CG. Nonpharmacologic management of behavioral symptoms in dementia. JAMA 2012;308:2020-9.

7. O'Neil ME, Freeman M, Christensen V, Telerant R, Addleman A, Kansagara D. A systematic evidence review of non-pharmacological interventions for behavioral symptoms of dementia. Washington (DC): Department of Veterans Affairs (US); 2011.

8. Tampi RR, Williamson D, Mittal V, McEnerney N, Thomas J, Cash M. Behavioral and psychological symptoms of dementia: part II-treatment. Clin Geriatr 2011;19:31-2, 34-40.

9. Fitzsimmons S, Barba B, Stump M. Diversional and physical nonpharmacological interventions for behavioral and psychological symptoms of dementia. J Gerontol Nur 2015;41:8-17.

10. Sloane PD, Hoeffer B, Mitchell CM, et al. Effect of person-centered showering and the towel bath on bathing-associated aggression, agitation, and discomfort in nursing home residents with dementia: a randomized, controlled trial. J Am Geriatr Soc 2004; 52:1795-804.

11. Corbett A, Smith J, Creese B, Ballard C. Treatment of behavioral and psychological symptoms of Alzheimer's disease. Curr Treat Options Neurol 2012;14: 113-25.

12. Ballard CG, Gauthier S, Cummings JL, et al. Management of agitation and aggression associated with Alzheimer disease. Nat Rev Neurol 2009;5:245-55.

13. Cooke ML, Moyle W, Shum DH, Harrison SD, Murfield JE. A randomized controlled trial exploring the effect of music on agitated behaviours and anxiety in older people with dementia. Aging Ment Health 2010;14:905-16.

14. Yang MH, Lin LC, Wu SC, Chiu JH, Wang PN, Lin JG. Comparison of the efficacy of aroma-acupressure and aromatherapy for the treatment of dementia-associated agitation. BMC Complement Altern Med 2015;15:93.
15. Gerdner LA, Hart LK, Zimmerman MB. Craniosacral still point technique: exploring its effects in individuals with dementia. J Gerontol Nur 2008;34: $36-45$.

16. Kerns JW, Winter JD, Winter KM, Kerns CC, Etz RS. Caregiver perspectives about using antipsychotics and other medications for symptoms of dementia. Gerontologist 2017;00:1-11. doi:10.1093/geront/ gnx042. Advance Access publication April 11, 2017.

17. Berry SD, Placide SG, Mostofsky E, et al. Antipsychotic and benzodiazepine drug changes affect acute falls risk differently in the nursing home. J Gerontol A Biol Sci Med Sci 2016;71:273-8.

18. Sink KM, Holden KF, Yaffe K. Pharmacological treatment of neuropsychiatric symptoms of dementia: a review of the evidence. JAMA 2005;293:596608.

19. Clerici F, Vanacore N, Elia A, et al; Memantine Lombardy Study Group. Memantine effects on behaviour in moderately severe to severe Alzheimer's disease: a post-marketing surveillance study. Neurol Sci 2012;33:23-31.

20. Miller LJ. The use of cognitive enhancers in behavioral disturbances of Alzheimer's disease. Consult Pharm 2007;22:754-62.

21. Seitz DP, Adunuri N, Gill SS, Gruneir A, Herrmann N, Rochon P. Antidepressants for agitation and psychosis in dementia. Cochrane Database Syst Rev 2011;(2):CD008191.

22. Porsteinsson AP, Drye LT, Pollock BG, et al; CitAD Research Group. Effect of citalopram on agitation in Alzheimer disease: the CitAD randomized clinical trial. JAMA 2014;311:682-91.

23. Konovalov S, Muralee S, Tampi RR. Anticonvulsants for the treatment of behavioral and psychological symptoms of dementia: a literature review. Int Psychogeriatr 2008;20:293-308.

24. Sommer OH, Aga O, Cvancarova M, Olsen IC, Selbaek G, Engedal K. Effect of oxcarbazepine in the treatment of agitation and aggression in severe dementia. Dement Geriatr Cogn Disord 2009;27:155-63.

25. Porsteinsson AP, Tariot PN, Erb R, et al. Placebocontrolled study of divalproex sodium for agitation in dementia. Am J Geriatr Psychiatry 2001;9:58-66.

26. Olin JT, Fox LS, Pawluczyk S, Taggart NA, Schneider LS. A pilot randomized trial of carbamazepine for behavioral symptoms in treatment-resistant outpatients with Alzheimer disease. Am J Geriatr Psychiatry 2001;9:400-5.

27. Ng B, Camacho A, Bardwell W, Sewell DD. Lamotrigine for agitation in older patients with dementia. Int Psychogeriatr 2009;21:207-8.

28. Buskova J, Busek P, Nevsimalova S. Gabapentin in the treatment of dementia-associated nocturnal agitation. Med Sci Monit 2011;17:CS149-51.

29. De Leon OA. Treatment of psychotic symptoms with lamotrigine in Alzheimer disease. J Clin Psychopharmacol 2004;24:232-3. 
30. Devanand DP, Pelton GH, D’Antonio K, et al. Lowdose lithium treatment for agitation and psychosis in alzheimer disease and frontotemporal dementia: a case series. Alzheimer Dis Assoc Disord 2017;31: $73-5$.

31. Devarajan S, Dursun SM. Aggression in dementia with lamotrigine treatment. Am J Psychiatry 2000; 157:1178.

32. Forester B, Vanelli M, Hyde J, et al. Report on an open-label prospective study of divalproex sodium for the behavioral and psychological symptoms of dementia as monotherapy and in combination with second-generation antipsychotic medication. Am J Geriatr Pharmacother 2007;5:209-17.

33. Herrmann N, Lanctot KL, Rothenburg LS, Eryavec G. A placebo-controlled trial of valproate for agitation and aggression in Alzheimer's disease. Dement Geriatr Cogn Disord 2007;23:116-9.

34. Lonergan E, Luxenberg J. Valproate preparations for agitation in dementia. Cochrane Database Syst Rev 2009;(3):CD003945.

35. Roane DM, Feinberg TE, Meckler L, Miner CR, Scicutella A, Rosenthal RN. Treatment of dementiaassociated agitation with gabapentin. J Neuropsychiatry Clin Neurosci 2000;12:40-3.

36. Sival RC, Haffmans PM, Jansen PA, Duursma SA, Eikelenboom P. Sodium valproate in the treatment of aggressive behavior in patients with dementia-a randomized placebo controlled clinical trial. Int J Geriatr Psychiatry 2002;17:579-85.

37. Olivieri-Mui BL, Devlin JW, Ochoa A, Schenck D, Briesacher B. Perceptions vs. evidence: therapeutic substitutes for antipsychotics in patients with dementia in long-term care. Aging Ment Health 2017;1 [Epub ahead of print].

38. Depakote [package insert]. North Chicago, IL: AbbVie Inc. Accessed November 2017 at https://www.depakote. com/hcp/important-safety-information.

39. Tegretol box warning. East Hanover (NJ): Novartis Pharmaceuticals Corp.; 2007. Available from: https:// www.accessdata.fda.gov/drugsatfda_docs/label/ 2007/018927s039lbl.pdf. Accessed March 29, 2017.

40. Lee PE, Gill SS, Freedman M, Bronskill SE, Hillmer MP, Rochon PA. Atypical antipsychotic drugs in the treatment of behavioural and psychological symptoms of dementia: systematic review. BMJ 2004;329:75.

41. Maher AR, Maglione M, Bagley S, et al. Efficacy and comparative effectiveness of atypical antipsychotic medications for off-label uses in adults: a systematic review and meta-analysis. JAMA 2011;306:1359-69.

42. Schneider LS, Dagerman KS, Insel P. Risk of death with atypical antipsychotic drug treatment for dementia: meta-analysis of randomized placebo-controlled trials. JAMA 2005;294:1934-43.

43. U.S. Food and Drug Administration. Public health advisory: deaths with antipsychotics in elderly patients with behavioral disturbances. April 11, 2005.
Available from: http://www.fda.gov/Drugs/Drug Safety/PostmarketDrugSafetyInformationforPatients andProviders/ucm053171.htm. Accessed August 26, 2016.

44. Information for healthcare professionals: conventional antipyschotics. June 16, 2008. Available from: http://www.fda.gov/Drugs/DrugSafety/Postmarket DrugSafetyInformationforPatientsandProviders/ ucm 124830.htm. Accessed November 20, 2017.

45. Press releases: Senators Blumenthal, Kohl, Grassley seek to protect the elderly and taxpayers from abusive overprescribing of antipsychotics. September 21, 2012. Available from: https://www.blumenthal. senate.gov/newsroom/press/release/senators-blumen thal-kohl-grassley-seek-to-protect-the-elderlyand-taxpayers-from-abusive-overprescribing-ofantipsychotics. Accessed September 6, 2016.

46. Informed consent for psychotropic medications for nursing home residents. Wisconsin Department of Health Services, Madison Wisconsin. Last revised December 11, 2015. Available from: http://www. dhs.wisconsin.gov/rl_dsl/NHs/psychtroMed.htm. Accessed June 8, 2017.

47. H.R.3545 - Omnibus Budget Reconciliation Act of 1987. 100th Congress. Available from: https://www. congress.gov/bill/100th-congress/house-bill/3545. Accessed June 12, 2017.

48. Centers for Medicare \& Medicaid Services. CMS announces national partnership to improve dementia care in nursing homes [press release]. May 30, 2012. Available from: https://www.cms.gov/Newsroom/ MediaReleaseDatabase/Press-Releases/2012-PressReleases-Items/2012-05-30.html. Accessed August 26, 2016.

49. Center for Clinical Standards and Quality/Survey \& Certification Group. Interim report on the CMS national partnership to improve dementia care in nursing homes: Q4 2011-Q1 2014. Baltimore: Department of Health \& Human Services, Centers for Medicare \& Medicaid Services. April 11, 2014. Available from: https://www.cms.gov/Medicare/ Provider-Enrollment-and-Certification/Survey CertificationGenInfo/Downloads/Survey-andCert-Letter-14-19.pdf. Accessed August 26, 2016.

50. Center for Clinical Standards and Quality/Survey \& Certification Group. Interim report on the CMS national partnership to improve dementia care in nursing homes. Baltimore: Department of Health \& Human Services, Centers for Medicare \& Medicaid Services. June 3, 2016. Available from: https://www. cms.gov/Medicare/Provider-Enrollment-andCertification/SurveyCertificationGenInfo/Down loads/Survey-and-Cert-Letter-16-28.pdf. Accessed March 1, 2017.

51. American Geriatrics Society Beers Criteria Update Expert Panel. American Geriatrics Society updated Beers Criteria for potentially inappropriate medication use in older adults. J Am Geriatr Soc 2012;60: 616-31. 
52. Best practice guideline for accommodating and managing behavioural and psychological symptoms of dementia in residential care: a person-centered interdisciplinary approach. Province of British Columbia, Canada: Ministry of Health. October 25, 2012. Available from: http://www.health.gov.bc.ca/library/ publications/year/2012/bpsd-guideline.pdf. Accessed September 6, 2016.

53. Challenging behaviors. Chicago: Alzheimer's Association; 2011. Available from: https://www.alz.org/ national/documents/statements_antipsychotics.pdf. Accessed September 6, 2016.

54. National Institute for Health and Care Excellence. Dementia: Supporting people with dementia and their careers in health and social care. Clinical guideline CG42. Published November 2006; updated September 2016. Available from: https://www.nice.org.uk/ guidance/CG42/chapter/1-Guidance\#interventionsfor-noncognitive-symptoms-and-behaviour-thatchallenges-in-people-with-dementia. Accessed September 6, 2016.

55. Reus VI, Fochtmann LJ, Eyler AE, et al. The APA practice guideline on the use of antipsychotics to treat agitation or psychosis in patients with dementia. Am J Psychiatry 2016;173:543-6.

56. Treatments for behavior. Chicago: Alzheimer's Association; 2017. Available from: http://www.alz.org/ alzheimers_disease_treatments_for_behavior.asp. Accessed June 12, 2017.

57. Leeman J, Sandelowski M. Practice-based evidence and qualitative inquiry. J Nurs Scholarsh 2012;44: 171-9.
58. Crabtree BF, Miller WL. Doing qualitative research. 2nd ed. Thousand Oaks (CA): Sage Publications; 1999.

59. Sandelowski M. Sample size in qualitative research. Res Nurs Health 1995;18:179-83.

60. Bradley EH, Curry LA, Devers KJ. Qualitative data analysis for health services research: developing taxonomy, themes, and theory. Health Serv Res 2007; 42:1758-72.

61. Carey JW, Morgan M, Oxtoby MJ. Intercoder agreement in analysis of responses to open-ended interview questions: examples from tuberculosis research. Cult Anthropol Methods 1996;8:1-5.

62. Ryan GW, Bernard HR. Techniques to identify themes. Field Methods 2003;15:85-109.

63. Gitlin LN, Winter L, Dennis MP, Hodgson N, Hauck WW. A biobehavioral home-based intervention and the well-being of patients with dementia and their caregivers: the COPE randomized trial. JAMA 2010;304:983-91.

64. Cornege-Blokland E, Kleijer BC, Hertogh CM, van Marum RJ. Reasons to prescribe antipsychotics for the behavioral symptoms of dementia: a survey in Dutch nursing homes among physicians, nurses, and family caregivers. J Am Med Dir Assoc 2012;13: 80.e1-6.

65. Woolf SH, Krist AH, Johnson RE, Stenborg PS. Unwanted control: how patients in the primary care setting decide about screening for prostate cancer. Patient Educ Couns 2005;56:116-24. 
Appendix

Abbreviated Interview Guide (Questions and

Prompts)

Demographics: Age/race/gender? How long in practice? What residency and other training have you had (eg, family medicine vs IM, geriatric certification?)

Do you see patients in their assisted living (AL) facility(ies)? (If yes, number of patients there.)

Do you see patients in their nursing home(s) $(\mathrm{NH})$ ? (If yes, number of patients there.)

Do you see patients from AL facilities in your office?

What patient dementia symptoms have been most challenging for you?

If psychiatric or behavior not brought up, ask about representative symptoms.

\section{Home}

Let's start by talking about patients living at home, not in AL facility or NH.

What kinds of nonpharmacologic approaches do you recommend to families for BPSD symptoms?

Please tell me a little bit about how you discuss this with families. Example?

How often do you think nonpharmacologic approaches are helpful?

Where did you learn about nonpharmacologic approaches?

Are there other things families need to help with nonpharmacologic approaches? (Access/ availability/resources?)

AL: Let's change focus to AL facilities.

Are nonpharmacologic approaches the same in $\mathrm{AL}$ facilities as in the community?

For AL facilities, could you tell me about any discussions or other communications you might have with families about nonpharmacologic approaches for BPSD? Example.

Can you tell me about any discussions or other communications you have about these approaches with AL staff? Fax/phone/in person?

Are there additional approaches you would like to see in AL facilities?

NH: Let's shift gears to NHs.

Are nonpharmacologic approaches the same for NHs versus AL facilities?

For NHs, could you tell me about any discussions or other communications you might have with families about nonpharmacologic approaches for BPSD? Example.
Can you tell me about any discussions or other communications you have about these approaches with NH staff? Fax/phone/in person?

Are there additional approaches you would like to see in $\mathrm{NH}$ ?

\section{Medications}

For medications, let's again start with patients in the community, not AL facilities or NHs.

Which medications do you use for BPSD symptoms in community patients?

Medications other than antipsychotics (APs)?

If not mentioned, ask about SSRIs, benzodiazepines, cognitive enhancers, Depakote, trazodone/ Remeron.

How does the decision to start a medication come about? Example?

Input: family, other people? Can you give me an example of a conversation?

When do you find medications helpful? Example?

Which medications do you find to be the most effective? In general, how helpful are they?

Better than nonpharmacologic methods? Keep people at home?

What problems from the medications do you see in patients?

Which are the most concerning? Example?

AL: Now let's discuss AL facilities.

Are medication approaches the same in ALs as in the community? Example?

Who all has input into the decision to start a medication for an AL patient? Example?

Input: nursing staff, family, other people? Can you give me an example?

What communication with families/Powers of Attorney (POAs) typically occurs when a medication is started in AL?

When do you find medications useful in AL facilities?

Which medications do you find the most helpful?

How helpful are they? Better than nonpharmacologic approaches?

What problems from the medications do you see in patients?

Which are the most concerning? Example? NH: Now let's discuss NHs.

Are medication approaches for $\mathrm{NH}$ patients the same as in AL facilities or the community? 
Who all has input into the decision to start a medication for a NH patient? Example?

Input: nursing staff, family, other people? Can you give me an example?

What communication with families/POAs typically occurs when a medication is started in the NH?

When do you find medications useful in NHs?

Which medications do you find the most helpful?

How helpful are they? Better than nonpharmacologic approaches?

What problems do you see in patients from the medications?

Which are the most concerning? Example?

\section{General Questions}

Do you typically make the diagnosis of dementia or do you refer such patients for diagnostic assistance? (Why?)

If referred, does the specialist continue to manage?
What diagnoses do you use for prescribing medications for BPSD?

Do the diagnoses differ in community versus AL facilities or NHs? Example?

Have state and other regulations affected your medication use for dementia/BPSD?

Guidelines/black box warnings?

Have black box warnings/guidelines affected the way you chart and document when prescribing medications? Example? (Have diagnoses changed?)

How is your role in managing BPSD similar or different than managing the other aspects of care these patients have?

Is dementia or BPSD management delegated at times?

Is delegation affected by black box warnings?

Do you see the severe adverse effects described in the black box warnings in your patients?

What else would you find helpful for prescribing for BPSD? For BPSD treatment overall? 